\title{
Novas exigências a Educação Ambiental no contexto pós- COVID-19: desafios a redefinição do Projeto Pedagógico
}

New demands on Environmental Education in the post-COVID-19 context: challenges to the redefinition of the Pedagogical Project

Nuevas demandas sobre Educación Ambiental en el contexto posterior a COVID-19: desafíos para la redefinición del Proyecto Pedagógico

Vilmar Alves Pereira (vilmar1972@gmail.com)

Bolsista de Produtividade do CNPq - Nível 2. Coordenador do Conselho de Educação da ARUTEMA. Grupo de Estudos sobre Fundamentos da Educação Ambiental e Popular (GEFEAP)

Marcel Jardim Amaral (marceljardimamaral1992@gmail.com) Bolsista da Coordenação de Aperfeiçoamento de Pessoal de Nível Superior - CAPES. Doutorando em Educação Ambiental pela Universidade Federal do Rio Grande (FURG). Grupo de Estudos sobre Fundamentos da Educação Ambiental e Popular (GEFEAP)

Resumo: Este ensaio tem a pretensão de provocar reflexões na redefinição do Projeto Pedagógico (PP) da escola a partir da possível contribuição da Educação Ambiental (EA). São reflexões de educadores ambientais que ao estarem vivenciando o contexto da COVID-19 se permitiram a buscar horizontes possíveis ao cenário pós-COVID-19 considerando a importância que a EA poderá estar assumindo. Desse modo, situa num primeiro momento, algumas problemáticas ambientais vivenciadas no mundo préCOVID-19; num segundo, apresenta sugestões e exigência à EA no amanhã da EA. De modo geral, os autores apresentam 10 princípios que apontam para mudanças de compreensões e para reafirmação de algumas pautas que podem contribuir para a garantia da vida quando em nossas escolhas políticas do PP refletirmos, debatermos e optarmos.

Palavras-chave: EA; COVID-19; PP.

Abstract: This essay intends to provoke reflections in the redefinition of the school's Pedagogical Project (PP) based on the possible contribution of Environmental Education (EA). These are reflections of environmental educators who, while experiencing the context of COVID-19, allowed themselves to seek possible horizons for the post-COVID-19 scenario considering the importance that EA may be assuming. In this way, it initially situates some environmental problems experienced in the pre-

Recebido em: $31 / 07 / 2020$

Aceito em: $1 \% / 12 / 2020$ 
COVID-19 world; in a second, it presents suggestions and demands to EA in EA's tomorrow. In general, the authors present 10 principles that point to changes in understandings and to reaffirm some guidelines that can contribute to the guarantee of life when in our political choices of the PP we reflect, debate and choose.

Keywords: EA; COVID-19; PP.

Resumen: Este ensayo tiene la intención de provocar reflexiones en la redefinición del Proyecto Pedagógico (PP) de la escuela basado en la posible contribución de la Educación Ambiental (EA). Estas son reflexiones de educadores ambientales que, mientras experimentaban el contexto de COVID-19, se permitieron buscar posibles horizontes para el escenario posterior a COVID-19 considerando la importancia que EA podría estar asumiendo. De esta manera, inicialmente sitúa algunos problemas ambientales experimentados en el mundo anterior a COVID-19; en un segundo, presenta sugerencias y demandas a EA en EA mañana. En general, los autores presentan 10 principios que apuntan a cambios en la comprensión y reafirman algunas pautas que pueden contribuir a la garantía de la vida cuando en nuestras elecciones políticas del PP reflexionamos, debatimos y elegimos.

Palabras-clave: EA; COVID-19; PP.

\section{St INTRODUÇÃO}

Iniciamos este ensaio reflexivo partindo da compreensão de que a COVID-19 alterou radicalmente a nossa vida e nosso modo de ser em todas as instâncias. Essas alterações, trazidas pela imperativa forma que a pandemia se impõe, trazem consigo reivindicações por mudanças em todos os campos da vida. De modo geral, elas emergem de constatações de que já não é mais possível agirmos da mesma forma como agíamos no mundo pré-COVID-19. Nesse ensaio, em específico estaremos refletindo sobre os desafios ao campo da EA e as exigências que emergem quando a escola tiver que repensar o seu PP. Quando realizávamos esse movimento junto aos docentes sempre utilizávamos como ponto de partida algumas indagações muito pertinentes:

Que sujeitos queremos formar? Que saberes queremos discutir? Que sociedade queremos para viver? Que escola queremos? Que educação queremos priorizar? Que avaliação precisamos construir? Que cultura queremos valorizar? Que conhecimento queremos trabalhar? Que relações de poder queremos manter? (PASSOS, 1995, p.15).

Recebido em: $31 / 07 / 2020$

Aceito em: $1 \% / 12 / 2020$ 
Ainda continuamos acreditando na potencialidade dessas indagações. No entanto, aproveitamos para acrescentar outras no tocante a EA: Qual a relação entre a COVID-19 e a crise do sistema capitalista? Que mudanças estruturais devemos realizar? Que outros reconhecimentos de saberes ambientais deveremos considerar? Quais são os desafios no que diz respeito ao aumento da exclusão no mundo pós-COVID-19? Como a EA pode ser compreendida na escola ao repensarmos nosso PP? Que perspectivas mais contundentes poderão ser assumidas pela EA na defesa e preservação da vida? E por que não se indagar sobre "como o espaço em sala de aula possibilita a articulação entre o trabalho diário da sala de aula na construção do conhecimento escolar por meio da EA, por exemplo? (UHMANN, 2019, p. 267).

Fazendo menção a um contexto pré-COVID-19 cabe destacar que o Brasil é conhecido internacionalmente por ser o país da Amazônia que sediou a ECO 92 e a Rio +20 , onde se discutiram os grandes temas sobre o Meio Ambiente, a Carta Brasileira sobre EA e Desenvolvimento Sustentável em confluência com a possibilidade de "(re)situar o papel e a pertinência da Educação Ambiental que se quer política, voltada para a participação dos cidadãos e cidadãs, tendo a cidadania e a ética como dois dos seus principais argumentos" (REIGOTA, 2010, p. 541). Assumem papel de destaque em nosso país as grandes lideranças tanto no que concerne à Educação Popular, dentre elas Paulo Freire, quanto no que consiste aos Movimentos Ambientalistas com expressões na figura de Chico Mendes, Leonardo Boff, entre tantos outros.

No plano legal, houveram muitos avanços com destaque para 1997, na aprovação dos Parâmetros Curriculares Nacionais (PCN), onde o Meio Ambiente é reconhecido como tema transversal; em 1999, foi aprovada a Lei ${ }^{\circ}$ 9.795, que dispõe sobre a Política Nacional de EA, com a criação da Coordenação-Geral de EA (CGEA) no Ministério de Educação (MEC) e da Diretoria de EA (DEA) no Ministério do Meio Ambiente (MMA). Em 2000, a EA integra, pela segunda vez, o Plano Plurianual (20002003). Após muitas lutas em 2002, a aprovação do Decreto ${ }^{\circ} 4.281$ regulamenta a Lei n 9.795 , de 27 de abril de 1999, que institui a Política Nacional de EA e dá outras providências, dentre elas, que a EA deve ser incluída em todos os níveis e modalidades de ensino.

Esses amplos movimentos permitiram que o Brasil assumisse também na América Latina um protagonismo nas questões de Formação de Educadores 
Ambientais, bem como no campo de investigação e adensamento epistemológico na área. É reconhecida a contribuição brasileira nas pesquisas em EA. Densos estudos de pesquisadores brasileiros tais como (Sato; Loureiro; e etc.); têm contribuído com a EA do mundo. Paradoxalmente, na atual conjuntura de governo (na figura do presidente, dos ministros da Educação e do Meio Ambiente) muitas dessas conquistas não estão sendo reconhecidas e estamos enfrentando inúmeras dificuldades nas questões ambientais e populares.

Dito isso, no presente ensaio abordaremos as novas exigências à EA no contexto pós-COVID-19, através do desafio presente da redefinição do PP com possibilidades de princípios que consideramos de extrema importância para dar novo sentido e/ou definição a este projeto.

\section{O PP E A EA NA FORMAÇÃO DE PROFESSORES/AS}

Para muito além de um documento obrigatório e estigmatizado por burocrático o PP é fundamental para orientar a comunidade escolar em especial aos educandos nas múltiplas relações de ensino-aprendizagem. "Desengavetá-lo" para visar a práxis e o diálogo das ações lá inseridas, requer de uma atenção especial no que tange a caracterização da instituição de ensino através da comunidade em que esta estiver inserida, para que haja o fortalecimento do corpo docente e consequentemente da qualidade do ensino. Para Moacir Gadotti “(...) construir o projeto pedagógico de uma escola é mantê-la em constante estado de reflexão e elaboração numa esclarecida recorrência às questões relevantes de interesse comum e, historicamente, requeridos" (GADOTTI, 2000, p. 71). Ou seja, é preciso avançar o estereótipo do "cumprimento de metas"; onde o PP carece de expressar no dia-a-dia dos sujeitos a caracterização do território inserido, da missão da instituição de ensino e os planos de ação e projetos que lá devem ser executados a partir do perfil da comunidade. Nessa perspectiva o PP para muito além da estigmatização de resumir-se a um plano de ensino e diversas atividades; também não pode ser analisado por “ algo que é construído e em seguida arquivado ou encaminhado às autoridades educacionais como prova do cumprimento de tarefas burocráticas. Ele é construído e vivenciado em todos os momentos por todos os envolvidos" (VEIGA, 1995, p. 12).

A concretude das ações e projetos podem e devem fragilizar as taxas de evasão / abandono, índices de reprovação, bem como trazer a efervescência de disciplinas 
críticas através da problematização com os professores para visar possíveis soluções as dificuldades encontradas. Aliás, sabe-se que o diálogo aqui - não se resume em uma metodologia da eficácia da participação, mas como uma possibilidade dos sujeitos serem inclinados a reflexão e a discussão da realidade de determinado objeto e a composição da instituição de ensino e a comunidade. Gadotti lembra-nos que,

\begin{abstract}
todo projeto supõe rupturas com o presente e promessas para o futuro. Projetar significa tentar quebrar um estado confortável para arriscar-se, atravessar um período de instabilidade e buscar uma nova estabilidade em função da promessa que cada projeto contém de estado melhor do que o presente. Um projeto educativo pode ser tomado como promessa frente a determinadas rupturas. As promessas tornam visíveis os campos de ação possível, comprometendo seus atores e autores. (GADOTTI, 1994, p. 579).
\end{abstract}

Neste sentido, podemos considerar que a formação permanente de professores/as no âmbito das instituições de ensino se articula na construção do PP com o intuito de estimular o compromisso com a formação do educando para a transformação da sociedade. Este projeto atrelado a EA - por exemplo, vem sendo objeto de inúmeros resultados e desafios através da participação coletiva, visto que os sujeitos são provenientes de fatores sociais e históricos, mediados pelo mundo imersos de uma " práxis social transformadora" (FREIRE, 1987, p. 80).

De modo geral reivindica algumas mudanças como a ampliação da compreensão da terra e do universo através da perspectiva de uma EA transformadora com o compromisso de uma política crítica ideológica contra-hegemônica, visto que “ na EA crítica, o conhecimento, para ser pertinente não deriva de saberes desunidos e compartimentalizados, mas da apreensão da realidade a partir de algumas categorias conceituais indissociáveis aos procedimentos pedagógicos" (MORIN, 2002, p. 45). Ou seja; o papel central da EA é garantir que as visões ecológicas de mundo possam ser "discutidas, compreendidas, problematizadas e incorporadas em todo tecido social e suas manifestações simbólicas e materiais, em um processo integral e integrador e sem imposição de uma única concepção hegemonicamente vista como verdadeira" (LOUREIRO, 2006, p. 39).

Para Freire "todo o projeto pedagógico é político e se acha molhado de ideologia. A questão a saber é a favor de que e de quem, contra que e contra quem se faz a política de que a educação jamais prescinde" (FREIRE, 1991, p. 44 - 45). Com isso, a conscientização crítica proporcionada pela EA no PP pode resultar na 
solidariedade à gaia, que despindo o desumanizado possibilita a transformação da espécie humana já que, "ser humano faz-se corresponsável, juntamente com as forças diretivas do universo e da natureza, pelo destino da humanidade e de sua casa comum, o planeta terra" (BOFF, 2003, p. 91).

Enquanto um novo paradigma, podemos dizer que a EA surge como uma possibilidade e/ou alternativa de transformação no âmbito de uma epistemologia que convoca a práxis da atividade pedagógica - articulando teoria e prática, diante da crise de sentido que se estabeleceu com a globalização, havendo a expansão da atuação humana no planeta, com a capacidade de destruir e/ou danificar as riquezas naturais. Cousin (2010) - por exemplo, compreende a EA numa perspectiva emancipatória que tem o intuito de "construir bases teóricas que possibilitem refletir e planejar ações educativas que busquem a construção de um modelo de sociedade com relações sociais para além da lógica capitalista dominante" (COUSIN, 2010, p. 176) ; contrariando o uso do pensamento "[...] que configura o esgotamento de um estilo de desenvolvimento ecologicamente predador, socialmente perverso, politicamente injusto, culturalmente alienado e eticamente repulsivo" (GUIMARÃES, 2001, p. 51).

Esse processo de conscientização através da EA no horizonte ontoepistemológico e ambiental contribui para pensarmos um PP eivado de reconhecimento e de sentido, de escutas e de diálogos múltiplos onde permite o alargamento a partir de novas visões e formas de lidar com o conhecimento a partir de valores mais democráticos - ou seja; no horizonte de uma ontoepistemologia ambiental “ adotar uma única forma de explicar e compreender a realidade torna-se insustentável. Em nosso alcance, essa compreensão promove uma grande abertura capaz de reconfigurar a educação ambiental, que pode assumir múltiplas interpretações” (PEREIRA; FREIRE; SILVA, 2019, p. 6).

Considerada a EA como um tema essencial no currículo da educação formal, destaca-se a projeção construtiva de uma rede de relações (culturais, sociais, políticas e econômicas), para além de um meio físico-biológico, há o destaque para a valorização da cidadania, da liberdade, democracia, pluralismo, do projeto societário, da ética, da sustentabilidade, do respeito e a não discriminação - ou seja, a concepção do meio ambiente em sua totalidade. Queremos afirmar com isso que, a EA consiste num horizonte formativo para a construção de sociedades sustentáveis tanto do ponto de vista social como o do ambiental.

Recebido em: $31 / 07 / 2020$

Aceito em: 1\%/12/2020 
Ao debruçar-se sobre a fecundidade da EA crítica, Loureiro relata que,

\begin{abstract}
a perspectiva crítica, não somente da Educação Ambiental, continua fecunda e é indispensável para a práxis transformadora em um momento que atingimos níveis impressionantes de concentração de riquezas, destruição de ecossistemas, extinção de espécies, expropriação material e imaterial de saberes e culturas, violência contra humanos e não-humanos e espoliação de direitos básicos que possibilitam nossa existência (LOUREIRO, 2019, p. 7576).
\end{abstract}

Neste trecho Loureiro afirma que a transformação da sociedade perpassa por uma perspectiva crítica, bem como de uma EA que incentive o fortalecimento da práxis emancipatória. A EA não se limita à educação formal, mas deve ser incluída e/ou inserida nesta, projetando assim a vida através de diálogos críticos com a realidade e o incentivo de proposições que tenham por base a autonomia e o entrelaçamento com a natureza, onde sua hermenêutica esteja em confluência com as diferentes formas de conhecimento e obviamente na formação cidadã projetando conscientização regional e planetária. Aliás, sabe-se que "é da natureza da EA pautar de estratégicas que para muito além do "verde", vise à "desintoxicação" deste sistema cruel e perverso (AMARAL; PEREIRA, 2018, p. 170), onde o campo ambiental influencia na "compreensão da existência e da importância da interdependência econômica, política, social e ecológica da sociedade" (DIAS, 2001, p. 83). Entendemos, portanto, que os processos formativos em EA vem constantemente questionando a construção dos PP, seja em instituições de ensino públicas ou privadas, do meio urbano ou rural; visto a fragilidade da abordagem sobre as expressões da questão ambiental, seus fundamentos, concepções e metodologias, já que a EA não atua apenas no plano epistemológico ou no da transmissão de informações " mas no da existência, em que o processo de conscientização se caracteriza pela ação com conhecimento, pela capacidade de fazermos opções, por se ter compromisso com o outro e com a vida" (LOUREIRO, 2006, p. 28).

No que concerne aos espaços de formação escolar as orientações políticas do Brasil pré - COVID-19 trazem inúmeras complicações dentre elas o não reconhecimento de grandes movimentos históricos e legais na defesa da temática ambiental como transversal, a mitigação do espaço da EA pré-COVID-19 com gigantescos desafios e com inúmeras interrogações sobre os caminhos da EA brasileira. Seguindo as orientações de agências internacionais ganha-se ênfase no Brasil a 
Educação Para a Sustentabilidade, bem como a agenda de desenvolvimento sustentável provocada pela Organização das Nações Unidas - ONU que apresenta para os países 17 objetivos de Desenvolvimento Sustentável dentre eles (erradicação da pobreza, fome zero e agricultura sustentável; água potável e saneamento, energia limpa e acessível, cidades e comunidades sustentáveis, consumo e produção responsáveis, ação contra mudança global do clima, vida na água, vida terrestre e outros). No entanto, como é de conhecimento não se atinge a sustentabilidade sem a EA. Daí há um estranhamento de muitos especialistas da EA sobre o frágil reconhecimento que a EA vem tendo no contexto Pré-COVID-19, bem como vem continuado no contexto da pandemia. Neste sentido compreendemos que esse fato sem dúvida traz implicâncias diretas em todos os níveis de Educação a começar pela Educação Básica.

\section{ALTERNATIVAS DA EA PARA O PP}

Há muito tempo convivemos com problemas que já expressavam a força de uma crise socioecológica com dimensões de proporções imensuráveis. Esta crise vem nos mostrando que não é possível a inserção de todos no universo consumista em função da limitação dos recursos naturais. O modelo de desenvolvimento deste sistema capitalista predatório gera um intenso conflito entre as classes, resultando na desigualdade da estrutura produtiva e na distribuição e apropriação dos bens, visto que o ciclo vicioso do capitalismo faz com que os seres humanos se reduzam a luta por sobrevivência ou pelas conquistas materiais fragilizando as confluências da natureza com a humanidade (REIGOTA, 2009). Basta lembrarmos alguns eventos ambientais que demonstram as grandes patologias socioambientais que vem afetado diretamente o planeta:

O desastre em Mariana, os terremotos no México, Tsunami no Japão. Posteriormente tivemos o Furacão Dorian, o poderoso Ciclone Idai em Moçambique, um novo desastre em Brumadinho, a maior liberação do uso de agrotóxicos no Brasil, o incentivo de exploração das terras indígenas e o aumento no número de mortes em muitas regiões, o desmatamento e o aumento das queimadas em grande área na Amazônia. Não bastasse as queimadas na Amazônia, fomos visitados pela fumaça das queimadas da Austrália, nos mostrando, que assim como os terremotos e demais eventos extremos, na natureza tudo está vinculado e os sinais vão aparecendo por todo o planeta. $\mathrm{O}$ sinal mais evidente desses eventos está nas mudanças climáticas e no descompromisso de muitos governos em nome da subserviência ao modelo de desenvolvimento do sistema capitalista predatório. (PEREIRA, 2020b, p. 21256). 
A chegada da COVID-19 agravou ainda mais as problemáticas vivenciadas anteriormente (PEREIRA, 2020a), neste caso trazemos a compreensão de que "a pandemia é um convite para 'sentir fazer pensar' novas relações com os outros. É tempo de aprendermos novos modos de criações com a natureza da qual somos parte, de buscarmos estabelecer novos acordos" (REIS; MENDONÇA; JÚNIOR, 2020, p. 47). Não é à toa que "uma das formas promissoras de pensar a função educativa na escola diz respeito a induzir ações concretas que possibilitem a formação de atitudes e valores, articuladamente ao desenvolvimento do currículo escolar" (UHMANN, 2019, p. 266). Ou seja; "ciências que se encontram em aliança com a ecologia de 'fazer e saberes' e se traduzem no âmbito da formação de educadores/as como potencializadora dos movimentos e encontros, e como oportunidade de implementação de pedagogias contra-hegemônicas" (REIS; MENDONÇA; JÚNIOR, 2020, p. 60).

Sendo a EA um campo em defesa radical da vida passamos a partir de agora elencar alguns princípios que consideramos ser fundamentais na reflexão quando formos repensar nosso PP no contexto pós COVID-19:

\section{O reconhecimento da crise da COVID-19 associada diretamente a crise do sistema} capitalista: consideramos ser esse um ponto fundamental para o estabelecimento inicial de qualquer debate sobre qualquer projeto em especial do PP que deve traduzir sim a vontade política de uma comunidade. Assim entendemos que a COVID-19 é mais uma das anomalias de um modelo de desenvolvimento insustentável e da forma como o sistema capitalista é um sistema de descuido com a vida. A evidência que fica, é, que no limite da vida que foi e que está sendo ameaçada, esse sistema se mostrou insuficiente para sua garantia mesmo nas grandes potências econômicas do mundo. A sugestão que trazemos é de que a escola pelo horizonte da EA problematize mais a crise socioecológica como uma crise do sistema capitalista na qual a COVID-19 escancarou as deficiências do referido sistema;

2. A reivindicação da mudança da matriz energética: estamos em pleno século XXI e ainda ouvimos o discurso de que nossa escola está a serviço do mercado de trabalho. $\mathrm{O}$ contexto pós COVID-19 deve pela EA colocar isso sob suspeita. Que mercado? O que alimenta esse mercado? Que energias movem esse mercado? Sugerimos pela EA ao 
contexto pós COVID-19 que a escola assuma no seu PP a adoção de ensino em defesa da matriz de energias renováveis e do abandono da matriz poluidora do Petróleo e do Carvão. Em nossa compreensão a COVID-19 abre possibilidades de repensar mais explicitamente nessa ruptura, quando nos damos por conta que a queda do valor de um barril de petróleo estava associada a baixa do consumo. Temos que trabalhar processos de conscientização ${ }^{1}$ pela rejeição dessa matriz e pela adoção de novas formas de energias mais limpas mudando também a perspectiva de educação a serviço da vida com interferências positivas no mundo do trabalho.

3. O reconhecimento de outros modos de se relacionar com o ambiente: no estabelecimento do nosso PP por vezes questionamos: que saberes queremos trabalhar ou reconhecer? Assim percebemos que algumas vezes ocorre a aceitação tácita de material didático preparado por outras pessoas e direcionado a realidade escolar, sendo que muitas vezes não dialogam com nossos contextos. Acreditamos que a EA pode contribuir muito no sentido de reforço de nossa identidade e pertencimento aos contextos e aos saberes sobre nossas origens. Nesse sentido em nosso Brasil e em nossa América Latina e Caribe existem inúmeros saberes ambientais dos povos tradicionais que além de demarcar melhor nossa origem reforçam o nosso pertencimento e preservam mais a vida.

4. O aumento da exclusão no mundo pós-COVID-19: Segundo a Comissão Econômica para a América Latina e Caribe (CEPAL, 2020) já tínhamos em nosso continente 190 milhões de pessoas em situação de pobreza. Após COVID-19 teremos 220 milhões, ou seja, 30 milhões a mais. A COVID-19 mostrou que entre os que sofrem, os excluídos de todos os matizes são os que sofrem mais. E ainda mais: nossa vida depende da saúde deles. Portanto o desafio em nosso PP: considerar o debate sobre a exclusão e as formas e/ou estratégias para diminui-la pensando em possibilidades de um futuro coletivo.

\section{A interdependência e o foco em atividades que reconheçam o ambiente inteiro: a} COVID-19 nos mostrou a impossibilidade de mantermos a lógica individualista de que

\footnotetext{
${ }^{1}$ A conscientização - aqui, para os autores está atrelada a necessidade da compreensão de que não há qualquer distinção entre o ser humano e a natureza, onde os homens/mulheres não podem controlar a gaia, já que são e fazem parte dela.
}

Recebido em: $31 / 07 / 2020$

Aceito em: 1\%/12/2020 
o problema do outro não é meu problema. Para pensarmos nosso PP temos que considerar o que a EA já vinha defendendo a tempo: a perspectiva de uma EA crítica que considere o ambiente inteiro e as múltiplas conexões que ocorrem no universo. Consideramos essa compreensão fundamental. Nesse sentido, reforçamos ainda mais a necessidade da transversalidade da EA em todos os tópicos de abordagem na escola.

6. A necessidade da mudança nas práticas de consumo: A COVID-19 nos fez perceber o quanto consumíamos e o que consumíamos. O Cenário Pós-COVID-19 pode sim nos ajudar a fazer algumas escolhas individuais, mas fundamentalmente coletivas na direção do consumo sustentável. Acreditamos que em nosso PP essa questão deve ser posta no sentido de orientação futura. Por isso vemos como necessária a pauta da Economia Solidária e da Agroecologia como perspectivas em favor da vida e o abandono a produção em grande escala para alimentar o mercado. Trata-se de um grande desafio, mas fundamentalmente de uma perspectiva ambiental com maior cuidado e respeito sobre o que consumimos e o que estamos alimentando com nosso consumo.

7. O cuidado ambiental como condição ontológica: já defendemos em outros textos que o capitalismo é um sistema de muito descuido. Vimos isso recentemente e estamos vivenciando essa luta de que a economia precede a vida. Ou seja, essa perspectiva que acredita que temos que sair do isolamento a qualquer custo. Posturas como essa em favor da economia são responsáveis pela perda de muitas vidas. Nosso PP a partir da EA deve orientar as ações na escola considerando o cuidado em todos os níveis como condição do nosso existir. Por isso uma educação que não considera o cuidado não pode ser ambiental. Reforçamos aqui a necessidade que teremos no mundo pós COVID-19 em pensarmos ações de cuidado com os excluídos e com o ambiente inteiro, que em apenas em 3 meses, deu sinais e respostas aos humanos, de que a natureza se sentiu mais aliviada e com melhor qualidade reconhecida em vários índices.

8. O reconhecimento do potencial político-formativo da EA como forma de intervenção no mundo: a partir da atual conjuntura que estamos vivendo a COVID-19

Recebido em: $31 / 07 / 2020$

Aceito em: $1 \% / 12 / 2020$ 
EA

assumirá

num

mundo

pós-

COVID-19 um papel ainda maior. Esse papel se dá tanto pelas inúmeras formas de preservação da vida, mas fundamentalmente pela problematização do sistema vigente. Nesse sentido, vemos com muita adequada orientação a perspectiva ecossocialista que sugere uma ruptura com a velhas práticas e princípios que orientam o capitalismo. Outrossim apontam para perspectivas, cooperativas, comunitárias, coletivas e solidárias em defesa da vida. Acreditamos que estamos numa nova encruzilhada e novamente com a possibilidade de escolha. Cabe a nós sabermos escolher o que almejamos em nosso PP $\mathrm{e}$, consequentemente, que sociedade queremos.

\section{O uso dos recursos e tecnologias como aprendizagem a distância sem esquecer do} papel fundamental do espaço de sala de aula presencial como espaço de educação do olhar: muitas polêmicas. Causadora de muitas polêmicas a Educação a distância no contexto da COVID-19 desacomodou e está desacomodando educadoras (es), familiares, dirigentes de escola e governos. De maneira geral criou um certo desconforto gerando inclusive interrogações sobre o papel da Educação Presencial. Acreditamos que por um lado mexeu na importância que damos no conjunto das atividades aos laboratórios que muitas escolas têm com pouca utilização. Também trouxe à tona as situações de que milhares de crianças, não tem recursos e acesso a redes em seu cotidiano. Por outro lado, também demonstrou a nossa limitação enquanto professores (as) no uso desses recursos. Questionou-se muito o papel das educadoras (es) pela família que também teve que aprender e acompanhar melhor seus filhos. No entanto as principais questões versam sobre o espaço e as formas de controles que o trabalho remoto está assumindo e assumirá em nossas vidas. Acreditamos que mesmo tendo gerado muitos movimentos e mesmo sendo o desejo de alguns dirigentes a educação a distância não irá no mundo pós-COVID-19 substituir as práticas tão significativas de Educação Presencial que possuem sentidos mais profundos. Temos que estar atentos pela ampliação do mercado que novamente aposta fortemente no setor em detrimento da presencial. Acreditamos serem complementares desde que não se precarizem as relações. Assim consideramos novamente ser questão de escolha política em nosso projeto sobre que educação queremos?

Recebido em: $31 / 07 / 2020$

Aceito em: $1 \% / 12 / 2020$ 
10. A pauta das mudanças climáticas: trata-se de um assunto que não é novidade, mas que, no entanto, sempre foi protelada ou trabalhada de maneira muito tênue em nossas escolas, salvo algumas experiências isoladas ou projetos pontuais. A COVID-19 nos impõe a necessidade urgente de que se quisermos garantir mais vida e evitar novos vírus, devemos encarar de fato a temática das mudanças climáticas. Elas refletem a invisibilidade que muitos governos atribuem a pauta ambiental por interesses políticos financeiros. Nesse momento no Brasil e na América Latina há muitas vidas sendo ceifadas pelos inúmeros processos de mineração. Há pouco tempo se tentou aprovar no Brasil a Medida provisória 910 conhecida como a MP do incentivo à grilagem aos povos da floresta dentre eles indígenas, pescadores artesanais, comunidades ribeirinhas, seringueiros, quilombolas, entre outros. O aumento dos índices de desmatamento, queimadas, liberação do uso de agrotóxicos, o grande uso das energias do petróleo e do carvão tem contribuído decisivamente nas alterações climáticas e na ocorrência de eventos extremos como já destacamos nesse texto. Associado a isso surge no campo ambiental os denominados hidronegócios com forte impacto e comércio sobre as águas. Acreditamos que escolas podem se colocar como projeto no desenvolvimento de pedagogias em favor da vida, no mundo pós COVID-19, estas devem considerar como horizonte ambiental possível no conjunto das atividades, a preocupação com uma formação que enfrente e crie alternativas as mudanças climáticas.

\section{INCONCLUSÕES}

Sabemos que a EA sozinha não consegue resolver todas as querelas do mundo. No entanto acreditamos que ela pode sim contribuir para o debate principalmente em contexto em que a vida é ameaça cotidianamente. A COVID-19 nos coloca no entre lugar entre o que éramos e o que almejamos ser. Sobre o que éramos e como agíamos podemos avaliar melhor. No entanto sobre o que seremos depende fundamentalmente das nossas escolhas. Nesse sentido estamos refletindo densamente nesses últimos meses sobre o valor a vida e sobre como será o amanhã da EA.

Acreditamos que as rotinas escolares não poderão mais voltar a ser como era antes. Aquela normalidade em que vivíamos não existe mais. Não podemos mais retornar para a sala de aula ignorando o grande sentido que a COVID-19 trouxe em nossas vidas. Todos/as fomos afetados/as! A dor de qualquer humano é nossa dor. 
Nesse sentido defendemos que a COVID-19 deve ampliar e sustentar em nós perspectivas de solidariedade planetária. $\mathrm{O}$ ato de educar é carregado de sentido existencial. Trata-se de uma prática com muitos cuidados em defesa da vida. Nesse horizonte, pensamos ser oportuno reuniões entre os/as docentes quando do retorno, e, em conjunto com suas equipes diretivas, problematizem as grandes questões ontológicas sobre o sentido da nossa ação educativa. E aí vemos oportuna a retomada do PP.

O que estamos sugerindo não consiste numa mudança simples do PP. Estamos sugerindo a problematização e compreensão da importância que a pauta da EA assume com maior sentido no mundo pós COVID-19. E isso traz mudanças profundas que sugerem adoção de uma escola voltada para o compromisso político com a vida. Esse compromisso vislumbra uma escola orientada por princípios mais ecológicos e por projetos coletivos e solidários. Para o atingimento dessa finalidade teremos muito trabalho formativo que necessitam de uma posição firme em seus PP's sobre o sentido de educar num mundo Pós-Covid-19. De modo muito singelo foi esse o convite que estamos fazendo a vocês através deste ensaio.

\section{REFERÊNCIAS}

AMARAL, Marcel Jardim; PEREIRA, Vilmar Alves. A coletividade em tempos temerosos: breve relato da parceria entre o PPGEA/FURG e o COMDESCCON. Ambiente \& Educação: Revista de Educação Ambiental, Rio Grande, v. 23, n. 2, p. 167-181, (Jul. /Dez. 2018).

BOFF, L. Ethos Mundial: um consenso mínimo entre os humanos. Rio de Janeiro: Sextante, 2003.

CEPAL, Comissão Econômica para América Latina e Caribe. Observatorio COVID19 en América Latina y el Caribe: Impacto económico y social. Disponível em: < https://www.cepal.org/es/temas/covid-19 >. Acesso em 13 maio 2020.

COUSIN, Cláudia da Silva. Pertencer ao naveg@r, agir e narr@r: a formação de educadores ambientais. 2010. 207 f. Tese (Doutorado em Educação Ambiental) Programa de Pós-Graduação em Educação Ambiental, Universidade Federal do Rio Grande, Rio Grande, 2010.

DIAS, G. F. Educação Ambiental: Princípios e Práticas. São Paulo: Gaia, 2001.

FREIRE, Paulo. A educação na cidade. 1. ed. São Paulo: Cortez Editora, 1991.

FREIRE, Paulo. Pedagogia do oprimido, 17. ed. Rio de Janeiro, Paz e Terra, 1987.

Recebido em: $31 / 07 / 2020$

Aceito em: $1 \% / 12 / 2020$ 
GADOTTI, Moacir. Perspectivas atuais da educação. Porto Alegre: Artes Médicas Sul, 2000.

GADOTTI, Moacir. Pressupostos do projeto pedagógico. In: MEC, Anais da Conferência Nacional de Educação para Todos. Brasília, 28/8 a 2/9/94.

GUIMARÃES, M. Educação ambiental: no consenso um embate? 4a ed. Campinas: Papirus, 2001.

LOUREIRO, C. F. B. A fecundidade da Educação Ambiental crítica. In: PEREIRA, Vilmar Alves; MALTA, Márcia Madeira (Orgs.). Ontologia da Esperança: A Educação Ambiental em tempos de crise. 1. ed. Juiz de Fora, MG: Editora Garcia, 2019, p. 75-90.

LOUREIRO, C. F. B. Trajetória e fundamentos da educação ambiental. São Paulo: Cortez, 2006.

MORIN, E. Ciência com consciência. Rio de Janeiro: Bertrand Brasil, 2002.

PEREIRA, Vilmar Alves. O que será o amanhã? Educação ambiental na América Latina e Caribe, justiça Ambiental e COVID-19. Juiz de Fora, MG: Garcia, 2020a.

PEREIRA, Vilmar Alves. Existências ameaçadas: a Educação Ambiental em tempos de COVID-19. The Brazilian Journal of Development (BJD). [S.1.], v. 6, n. 4, p. 2125421271, abr. 2020b. ISSN 2525-8761. Disponível em: < https://www.brazilianjournals. com/index.php/BRJD/article/view/ 9223/7791 >. Acesso em 11 junh. 2020. doi: https://doi.org/10.34117/bjdv6n4-337.

PEREIRA, Vilmar Alves; FREIRE, Simone Grohs; SILVA, Márcia Pereira da. Ontoepistemologia Ambiental: vestígios e deslocamentos no campo dos fundamentos da educação ambiental. Pro-Posições, Campinas, v. 30, e20180011, 2019. Disponível em: < https://www.scielo.br/scielo.php?script=sci_arttext\&pid=S0103-7307201900010 0532. Acesso em 28 de julho, 2020. doi: http://dx.doi.org/10.1590/1980-6248-2018$\underline{0011}$.

PEREIRA, Vilmar Alves. Ecologia Cosmocena: a redefinição do espaço humano no cosmos. Juiz de Fora, MG: GARCIA edizioni, 2016.

REIGOTA, Marcos. A Educação Ambiental frente aos desafios apresentados pelos discursos contemporâneos sobre a natureza. Educ. Pesqui. [online]. 2010, vol.36, n.2 [cited 2020-07-28], p.539-570. Disponível em: < https://www.scielo.br/scielo.php?pid=S1517-97022010000200008\&script=sci_abstract \&tlng=pt >. ISSN 1517-9702. doi: https://doi.org/10.1590/S1517-97022010000200008.

REIGOTA, Marcos. O que é Educação Ambiental? 2. ed. São Paulo: Brasiliense, 2009.

Recebido em: $31 / 07 / 2020$

Aceito em: 1\%/12/2020 
Vol. 3, n. 5. Set./Dez.

ISSN: 2595- 4520

REIS, Leonardo Rangel dos; MENDONÇA, Rosa Helena; JÚNIOR, Ivan de Matos e Silva. Adiando o fim do mundo em tempos de pandemia: potências do 'sentirfazerpensar' com gestos e histórias. REMEA - Revista Eletrônica do Mestrado em Educação Ambiental. v. 37, n. 2, p. 43-64, junho 2020. ISSN 1517-1256. Disponível em: < https://periodicos.furg.br/remea/article/view/11185 >. Acesso em: 12 jul. 2020. doi: https://doi.org/10.14295/remea.v0i0.11185

UHMANN, R. Estratégias formativas na formação inicial e continuada de professores de Ciências. Revista Insignare Scientia - RIS, v. 2, n. 3, p. 262-269, 21 nov. 2019. ISSN 2595-4220. Disponível em: < https://periodicos.uffs.edu.br/index.php/ RIS/article/view/11206 >. Acesso em: 11 jul. 2020. doi: https://doi.org/10.36661/2595$\underline{4520.2019 \mathrm{v} 2 \mathrm{i} 3.11206}$

VEIGA, Ilma Passos Alencastro. Projeto Político Pedagógico da Escola: uma construção possível. Campinas SP: Papirus, 1995.

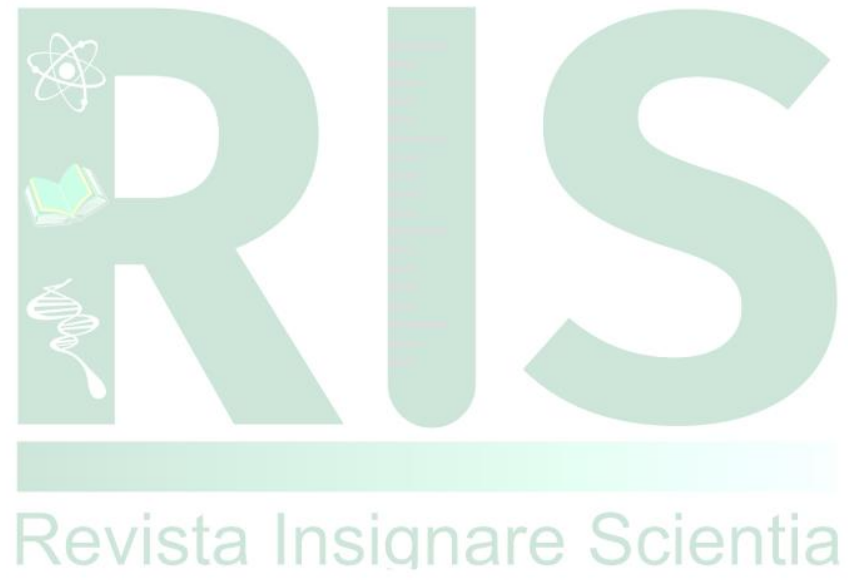

Recebido em: $31 / 07 / 2020$

Aceito em: $1 \% / 12 / 2020$ 